\title{
Effects of daily SKF 38393, quinpirole, and SCH 23390 treatments on locomotor activity and subsequent sensitivity to apomorphine*
}

\author{
Bruce A. Mattingly, James K. Rowlett, and Greg Lovell \\ Department of Psychology, 601 Ginger Hall, Morehead State University, Morehead, KY 40351, USA
}

Received June 8, 1992 / Final version July 28, 1992

\begin{abstract}
In three experiments, male Wistar rats (250-350 g) were injected (SC) daily with the $D_{1}$-type dopamine receptor agonist, SKF $38393(0.0,4.0,8.0$, or $16.0 \mathrm{mg} / \mathrm{kg}$ ), the $D_{2}$-type dopamine receptor agonist, quinpirole $(0.0,0.3$, or $3.0 \mathrm{mg} / \mathrm{kg})$, and/or the $D_{1}$-type dopamine receptor antagonist, SCH $23390(0.0$ or 0.5 $\mathrm{mg} / \mathrm{kg}$ ) for 8-10 days. After each daily injection, the rats were tested for locomotor activity in photocell arenas for $20 \mathrm{~min}$. Following this subchronic pretreatment, all rats were challenged with the mixed dopamine receptor agonist apomorphine $(1.0 \mathrm{mg} / \mathrm{kg}, \mathrm{SC})$ and tested for locomotor activity. SKF 38393 treatments produced a dosedependent decrease in locomotor activity which did not significantly change across days. Quinpirole also depressed locomotor activity when first injected, but this quinpirole-induced inhibition of activity progressively decreased across days. When subsequently, challenged with apomorphine, rats in both the SKF 38393 and the quinpirole pretreatment groups displayed greater loco- motor activity than rats pretreated with only vehicle. Although SCH 23390 pretreatments did not affect subsequent sensitivity to apomorphine, SCH 23390 completely blocked the effect of quinpirole. These results suggest that although repeated $D_{1}$ receptor stimulation may be sufficient to induce behavioral sensitization to apomorphine, $D_{2}$ receptor stimulation also contributes to the effect.
\end{abstract}

Key words: Behavioral sensitization - Apomorphine SKF 38393 - Quinpirole - SCH 23390 - Locomotor activity

The repeated administration of drugs that stimulate dopamine receptors often results in the development of behavioral sensitization (see Robinson and Becker 1986; Kalivas and Weber 1988). This behavioral sensitization

* Portions of this paper were presented at the 1991 Society for Neuroscience meetings, New Orleans, La, USA.

Corréspondence to: B.A. Mattingly effect has been demonstrated in rats with both direct (e.g., apomorphine) and indirect (amphetamine, cocaine) dopamine agonists and is characterized by a progressive augmentation of various drug-induced motor behaviors (e.g., Kalivas and Weber 1986; Robinson and Becker 1986; Mattingly et al. 1988). Although recent evidence clearly indicates that stimulation of dopamine receptors is neccessary for the development of behavioral sensitization (e.g., Kuczenski and Leith 1981; Mattingly and Rowlett 1989; Peris and Zahniser 1989), the specific drug-induced neurobiological changes mediating the development of behavioral sensitization are unknown.

Dopamine agonists which induce the development of behavioral sensitization (e.g., apomorphine, amphetamine, and cocaine) result in an increased stimulation of both $D_{1}$-type and $D_{2}$-type dopamine receptors. In a recent study of apomorphine-induced sensitization, we found that concurrent treatments of rats with the $\mathrm{D}_{1}$-type dopamine antagonist, $\mathrm{SCH} 23390$, blocked both the acute locomotor-activating effects of apomorphine and the development of behavioral sensitization. In contrast, the $\mathrm{D}_{2}$-type dopamine receptor antagonist, sulpiride, blocked the acute effects of apomorphine, but did not prevent the development of behavioral sensitization (Mattingly et al. 1991). Similarly, amphetamine-induced behavioral sensitization may be blocked by $D_{1}$, but not $\mathrm{D}_{2}$-type, dopamine receptor antagonists (Stewart and Vezina 1989; Vezina and Stewart 1989). These findings, of course, suggest that repeated stimulation of the dopamine $D_{1}$-type receptor is both necessary and sufficient to induce the development of behavioral sensitization. In the present study, we tested this assumption by treating rats daily with either the selective $\mathrm{D}_{1}$-type dopamine agonist, SKF 38393 (expt 1) or the $\mathrm{D}_{2}$-type agonist, quinpirole (expt 2), and testing for locomotor activity. Following this subchronic pretreatment, all rats were then tested for locomotor activity after a challenge injection of the mixed $\mathrm{D}_{1} / \mathrm{D}_{2}$ agonist, apomorphine. Based upon our prior work, we expected the rats pretreated with SKF 38393, but not quinpirole, to demonstrate behavioral sensitization to apomorphine. 


\section{Experiments 1 and 2}

\section{Materials and methods}

Subjects. Seventy-three male Wistar albino rats (Harlan Industries, Indianapolis, IN) weighing between 250 and $350 \mathrm{~g}$ served as subjects. All rats were housed individually in hanging wire-mesh cages in a colony room with a 12-h light-dark cycle and food and water available continuously. All behavioral testing was conducted during the light phase of the cycle.

Apparatus. Activity measures were taken in two BRS/Lehigh Valley cylindrical activity drums (Model 145-03). The floor of each drum was made of $4 \mathrm{~cm}$ diamond-shaped wire mesh and was $60 \mathrm{~cm}$ in diameter. The interior wall of each drum was painted flat black and was $43 \mathrm{~cm}$ high. Each drum was located in a separate soundattenuated experimental cubicle that was kept dark during testing.

Two banks of three infrared photocells were mounted on the outside of each drum. The six photocell beams were approximately $12 \mathrm{~cm}$ apart arranged in a criss-cross pattern $2.5 \mathrm{~cm}$ above the drum floor. The photocell banks were connected to back-path eliminator diodes. Movement of the rat through a photocell beam sent a single pulse to the counters. Simultaneous pulses (i.e., pulses spaced less than $0.05 \mathrm{~s}$ apart) such as might occur when two beams are broken at their intersection were recorded as a single count by this method. Thus, locomotor activity was operationalized as the cumulative number of photocell interruptions per unit time.

Drugs. Apomorphine hydrochloride (Sigma) and SKF 38393 (Research Biochemicals) were dissolved daily in 0.001 N HCL. Apomorphine was injected in a volume of $1.0 \mathrm{ml} / \mathrm{kg}$ and SKF 38393 was injected in a volume of $1.5 \mathrm{ml} / \mathrm{kg}$. Quinpirole hydrochloride (Research Biochemicals) was mixed in distilled $\mathrm{H}_{2} \mathrm{O}$ and injected in a volume of $1.0 \mathrm{ml} / \mathrm{kg}$. All injections were SC. Control injections were given using the appropriate vehicle using the same route and volume as the corresponding drug injection.

Design and procedure. At the beginning of experiment 1, 48 rats were randomly assigned, in equal numbers, to one of four treatment groups: 0 (vehicle), $4.0,8.0$, or $16.0 \mathrm{mg} / \mathrm{kg}$ SKF 38393 . On each of the first 10 days of the experiment (pretreatment phase), the rats were injected with the appropriate dose of SKF 38393 and then tested for locomotor activity $15 \mathrm{~min}$ after the injection. Locomotor activity measurements were taken for $20 \mathrm{~min}$ each day. On day 11 of the experiment all rats were given a challenge injection of apomorphine $(1.0 \mathrm{mg} / \mathrm{kg})$ and then tested for activity $15 \mathrm{~min}$ later. Experiment 2 was the same as experiment 1 except three groups of rats $(N=8-9 /$ group) were given either 0 (vehicle), 0.3 , or $3.0 \mathrm{mg} / \mathrm{kg}$ quinpirole during the pretreatment phase.

Data analysis. Significant differences among the groups in mean activity counts across days were determined with mixed-factor analyses of variance (ANOVA) using drug treatment group as a between factor and daily test session as a repeated measure. When appropriate, additional one-way ANOVAs or Neuman-Keuls post hoc test were performed.

\section{Results}

Expt 1: chronic SKF 38393 and activity. The mean activity counts for the four groups injected daily with various doses of SKF 38393 across the first ten test days are shown in Fig. 1. As may be seen in this figure, rats injected with SKF 38393 were significantly less active than the vehicle control rats on the first test day. Moreover, this drug-induced decrease in locomotor activity was dose-dependent and was maintained relatively un-

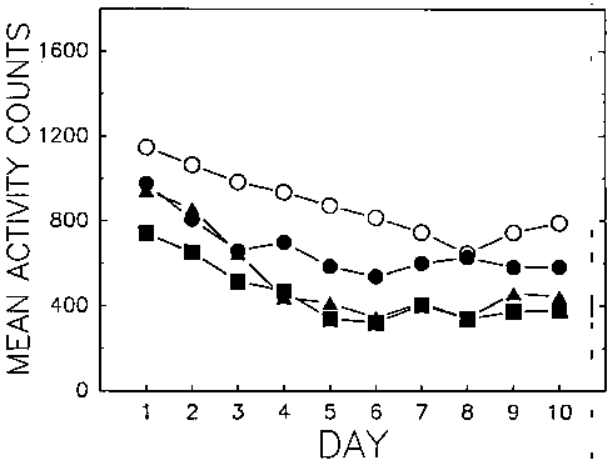

Fig. 1. Mean activity counts per 20 min' session across the 10 pretreatment days for rats ( $N=12 /$ group) injected with either vehicle $(\mathrm{O}-\mathrm{O})$ or SKF 38393. SKF 38393: $4.0 \mathrm{mg} / \mathrm{kg}(\bullet-\bullet)$; $8.0 \mathrm{mg} / \mathrm{kg}(4-4) ; 16.0 \mathrm{mg} / \mathrm{kg}(\mathbf{-}-\mathbf{C})$. The standard error of the mean for the groups' activity on day 10 was 65.25

changed across the ten daily injection-test sessions. That is, although the groups gradually decreased activity with repeated testing, the activity of the SKF 38393 groups, particularly the 8.0 and $16.0 \mathrm{mg} / \mathrm{kg}$ groups, remained significantly lower than that of the vehicle control rats. The ANOVA performed on these data revealed a significant drug effect $[F(3,44)=12.10, P<0.0001]$, day effect, $[F(9,396)=50.64, P<0.0001]$, and Drug $\times$ Day interaction, $[F(27,396)=1.89, P<0.01]$. This latter interaction was largely due to the fact that the groups decreased activity at slightly different rates over the first 3 test days.

Expt 1: apomorphine challenge of SKF 38393 pretreated rats. The mean activity counts of the four pretreatment groups after a challenge injection of apomorphine $(1.0 \mathrm{mg} / \mathrm{kg})$ on test day 11 are shown in Fig. 2. As shown in this figure, rats previously given ten daily injections of SKF 38393 displayed significantly greater levels of locomotor activity in response to the apomorphine challenge injection than rats previously treated with only vehicle. As expected, the ANOVA performed on these data revealed a significant drug effect, $[F(3,44)=3.55, P<0.05]$. Subsequent analysis of this drug effect with NewmanKeuls post hoc tests indicated that all three SKF 38393

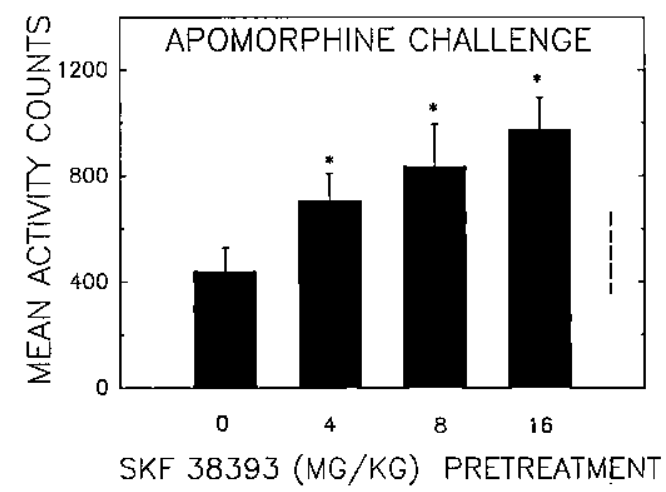

Fig. 2. Mean activity counts ( $+\mathrm{SEM}$ ) during the 20 min session following a challenge injection of apomorphine for rats ( $N=12 /$ group) previously treated daily with either vehicle or SKF 38393. ( ${ }^{*} P<0.05$ vs $0 \mathrm{mg} / \mathrm{kg}$ group) 
pretreatment groups were significantly more active following apomorphine than the vehicle control group $\left(P_{\mathrm{S}}<0.05\right)$.

Expt 2 : chronic quinpirole and activity. The mean activity counts for the three groups of rats injected daily with either quinpirole or vehicle are displayed in Fig. 3. As may be seen in this figure, quinpirole induced a significant depression in locomotor activity following the first injection. This quinpirole-induced inhibition of locomotor activity, however, progressively decreased with repeated injections. Indeed, by day 4 of testing the rats injected with quinpirole did not differ significantly from those injected with vehicle, and by the end of testing quinpirole-treated rats were more active than vehicletreated rats. The ANOVA performed on these data indicated that the main effect of drug was not significant. As expected, however, both the main effect of day and the Drug $\times$ Day interaction were significant $[F(9,198)=13.95, \cdot P<0.0001$, and $F(18,198)=9.49$, $P<0.0001$, respectively]. To further analyse this interaction, a one-way ANOVA was performed on the rats' activity scores on the last pretreatment test day (10). The results of this analysis revealed no significant differences in activity among the groups $(P>0: 05)$. Thus, the quin-

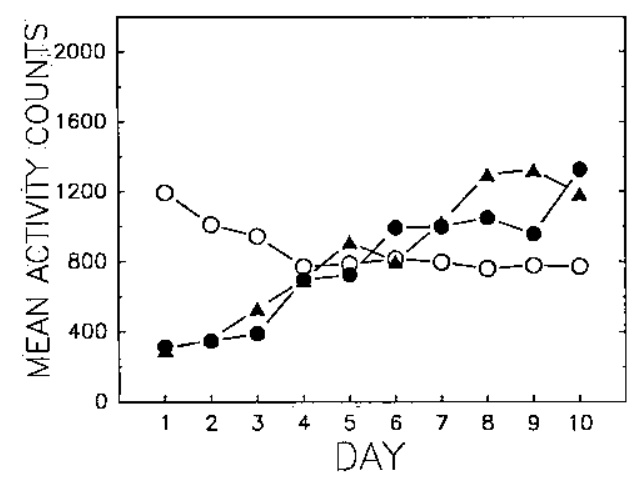

Fig. 3. Mean activity counts per $20 \mathrm{~min}$ session across the 10 pretreatment days for rats $(N=8-9 /$ group $)$ injected with either vehicle $(\mathrm{O}-\mathrm{O})$ or quinpirole. Quinpirole: $0.3 \mathrm{mg} / \mathrm{kg}(-\bullet)$; $3.0 \mathrm{mg} / \mathrm{kg}(\boldsymbol{\Delta}-\boldsymbol{\Delta})$. The standard error of the mean for the groups' activity on day 10 was 179

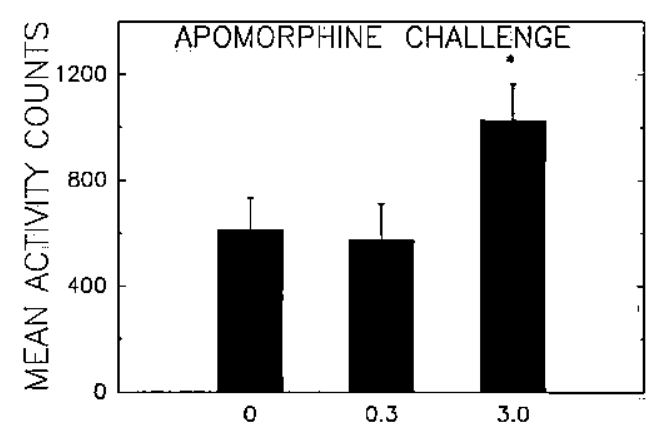

QUINPIROLE (MG/KG) PRETREATMENT

Fig. 4. Mean activity counts per 20 min session ( + SEM) following a challenge injection of apomorphine for the three groups of rats $(N=8-9$ each) previously treated daily with either vehicle or quinpirole. $\left({ }^{*} P<0.05\right.$ vs $0 \mathrm{mg} / \mathrm{kg}$ group) pirole-treated rats were not significantly more active than the vehicle-treated rats on this test day."

Expt 2: apomorphine challenge of quinpirole pretreated rats. The mean activity counts of the three quinpirole pretreatment groups after a challenge injection of apomorphine on day 11 of testing are shown in Fig. 4. It is evident from this figure that the rats pretreated for 10 days with $3.0 \mathrm{mg} / \mathrm{kg}$ quinpirole displayed significantly greater locomotor activity in response to a challenge injection of apomorphine than did either the vehiclecontrol group or the $0.3 \mathrm{mg} / \mathrm{kg}$ quinpirole pretreatment group. As expected, the ANOVA performed on these data revealed a significant drug effect $[F(2,24)=3.75$, $P<0.05]$.

\section{Experiment 3}

In experiment 2 , rats pretreated with the $D_{2}$ receptor agonist, quinpirole displayed significantly greater levels of locomotor activity following an apomorphine injection than did rats pretreated with vehicle. This finding was unexpected because our previous work had indicated that rats repeatedly treated with the mixed $D_{1} / D_{2}$ dopamine receptor agonist, apomorphine, along with the selective $D_{1}$ dopamine antagonist SCH 23390 do not become sensitized to apomorphine (Mattingly et al. 1991). This apparent discrepancy in the effects of repeated $D_{2}$ receptor stimulation may be related to the presence or absence of $D_{1}$ "tone". That is, repeated $D_{2}$ receptor stimulation may have been effective in expt 2 because the $D_{1}$ receptors were not blocked as they were in our previous study. If so, then the effects of repeated quinpirole treatments, like apomorphine treatments, should be blocked by concurrent treatments with the $\mathrm{D}_{1}$ receptor antagonist, SCH 23390 . In experiment 3 , therefore, groups of rats were injected daily with quinpirole and/or SCH 23390 for 8 days and then tested for locomotor activity after a challenge injection of apomorphine.

\section{Materials and methods}

Subjects, apparatus, and drugs. The subjects were 32 male Wistar albino rats (Harlan Industries, Indianapolis, IN) weighing between 250 and $300 \mathrm{~g}$ at the beginning of the experiment. The apparatus was the same as in the preceding experiments. Likewise, quinpirole and apomorphine were obtained, prepared, and administered as described previously. SCH 23390 (Research Biochemicals, Inc.) was dissolved daily in distilled $\mathrm{H}_{2} \mathrm{O}$ and injected $\mathrm{SC}$ in a volume of $1.0 \mathrm{ml} / \mathrm{kg}$.

Design and procedure. The rats were randomly assigned, in equal numbers, to one of four groups comprising the two (SCH 23390 dose: 0 or $0.5 \mathrm{mg} / \mathrm{kg}$ ) $\times$ two (quinpirole dose: 0 or $3.0 \mathrm{mg} / \mathrm{kg}$ ) factorial design. On day 1 of the pretreatment phase each rat was first injected with either vehicle or SCH 23390 and returned to its home cage. Fifteen minutes later each rat was injected with either quinpirole or vehicle and again returned to its home cage. Fifteen minutes after the second injection each rat was placed into the activity drum and activity counts were recorded for $20 \mathrm{~min}$. This injection-test procedure was repeated daily for 8 days. On day 9 , all 
rats were given a challenge injection of apomorphine $(1.0 \mathrm{mg} / \mathrm{kg})$ and tested for activity $15 \mathrm{~min}$ after the injection.

\section{Results}

Expt 3: quinpirole, SCH 23390 , and activity. The mean activity counts of the four groups across the eight pretreatment sessions are presented in Fig. 5. As may be seen in this figure, rats injected with SCH 23390 and/or quinpirole were significantly less active on day 1 than rats injected with only vehicle. Further, the SCH 23390 -induced inhibition of locomotor activity did not significantly change across the 8 pretreatment days. In contrast, the quinpirole-induced inhibition of locomotor activity decreased significantly across the pretreatment days for rats injected with vehicle, but not for those injected with SCH 23390. That is, concurrent SCH 23390 treatments completely blocked the increase in activity observed across days in quinpirole-injected rats. The three-factor ANOVA performed on these data revealed a significant main effect for SCH $23390[F(1,28)=74.60$, $P<0.0001$, and several significant interactions including the SCH $23390 \times$ Quinpirole $\times$ Day interaction $[F(7,196)$ $=8.35, P<0.0001]$. To further analyse this latter interaction, a separate ANOVA was performed on the last pretreatment day (day 8) alone. Consistent with the above interpretation, this analysis revealed a significant main effect of SCH $23390[F(1,28)=50.37, P<0.0001]$, however, neither the main effect of quinpirole nor the $\mathrm{SCH} 23390 \times$ Quinpirole interaction was significant $[F \mathrm{~s}<1.00]$. Thus, at the end of the pretreatment phase, rats injected with SCH 23390 remained significantly less active then the vehicle control rats, whereas rats treated daily with only quinpirole did not significantly differ from rats injected daily with only vehicle.

Expt 3: apomorphine challenge of SCH 23390/quinpirole pretreated rats. The mean activity counts of the four groups of rats after the challenge injection of apomorphine on day 9 of testing are presented in Fig. 6. Consistent with the results of experiment 2, rats pretreated for 8 days with only quinpirole displayed significantly

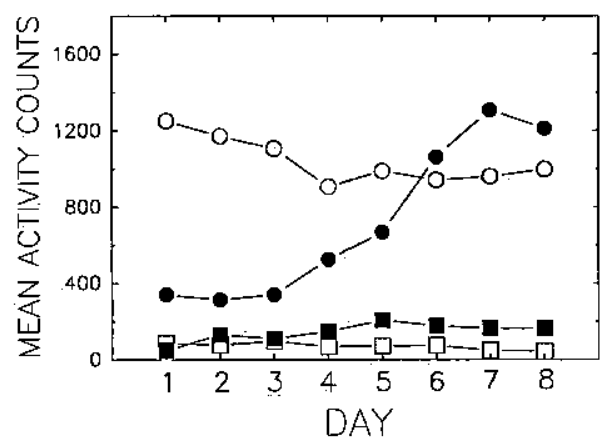

Fig. 5. Mean activity counts per 20 min session across the 8 pretreatment days for the four groups of rats ( $N=8$ /group) injected daily with either vehicle $(V)$ or SCH $23390(S)$ followed by either vehicle

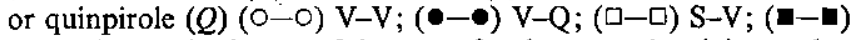
$\mathrm{S}-\mathrm{Q}$. The stardard error of the mean for the groups' activity on day 8 was 101

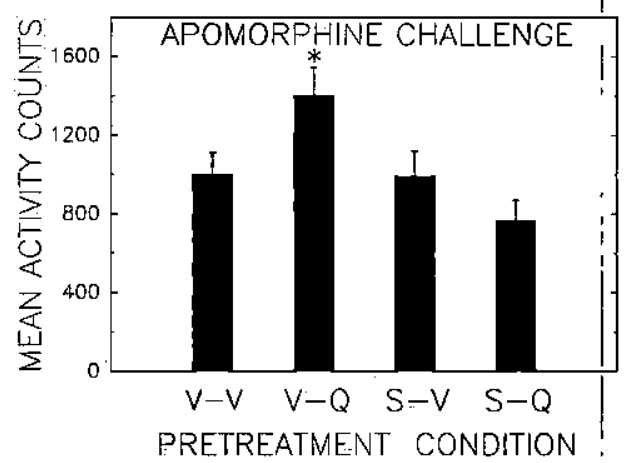

Fig. 6. Mean activity counts per 20 min session (+SEM) following a challenge injection of apomorphine for groups of rats $(N \doteqdot 8 /$ group) previously treated for 8 days with either vehicle $(V)$ or SCH $23390(S)$ followed by either vehicle $(V)$ or quinpirole $(Q)$. ( $P<0.05$ vs $\mathrm{V}-\mathrm{V}$ group)

greater locomotor activity following an injection of apomorphine than did rats pretreated with only vehicle. In contrast, the activity of rats pretreated with only SCH 23390 for 8 days did not differ significantly from the vehicle-only group on this test day. More important, rats pretreated with both SCH 23390 and quinpirole for 8 days did not differ from the vehicle control group. In other words, concurrent treatments of rats with $\mathrm{SCH} 23390$ blocked the effects of repeated quinpirole treatments on apomorphine-induced activity. Consistent with this interpretation, the ANOVA performed on these data revealed a significant main effect of $\mathrm{SCH} 23390$ $[F(1,28)=8.44, \quad P<0.01]$ and a significant $\mathrm{SCH}$ $23390 \times$ Quinpirole interaction $[F(1,28)=8.01, P<0.01]$. A Neuman-Keuls analysis of this significant interaction indicated that the vehicle-quinpirole rats were significantly more active than the other three groups, $[P \mathrm{~s}<$ $0.05]$. None of the other group comparisons were significant.

It might be noted that in this experiment the rats previously given only vehicle displayed greater activity following the apomorphine challenge injection than in either of the preceding two experiments. Moreover, in contrast to the first two experiments, apomorphine did not produce a decrease in activity in vehicle rats relative to their activity level following vehicle on the preceding day. This variability in the initial effects of apomorphine is not unusual. Moreover, the lack of an apomorphineinduced increase in activity following the first injection of apomorphine is consistent with our previous work (see Mattingly et al. 1988, 1991; Mattingly and Gotsick 1989; Rowlett et al. 1991). It should be emphasized, however, that the development of behavioral sensitization to apomorphine is a highly reliable and robust phenomenon, and despite changing baselines, the relative effects of various treatments on apomorphine-induced locomotor activity have also been reliable across experiments (cf, quinpirole groups in Figs. 4 and 6).

\section{Discussion}

It is evident from the present results that selective stimulation of the $\mathrm{D}_{1}$-type dopamine receptor with SKF 38393 
in rats significantly inhibited locomotor activity, Moreover, this inhibition was dose-dependent and did not significantly change with repeated treatments. The $\mathrm{D}_{2^{-}}$type dopamine receptor agonist, quinpirole, also decreased locomotor activity when first administered, but this inhibition rapidly decreased with repeated treatments. In fact, with repeated treatments quinpirole appeared to have a stimulating effect on locomotor activity relative to the vehicle treated rats. Whether this increase in activity with repeated quinpirole treatments should be interpreted as tolerance or sensitization, however, is unclear, since the quinpirole treated rats were not significantly more active than the vehicle treated rats at the end of training. Although the time course is quite different, the direct $\mathrm{D}_{2}$-type dopamine receptor agonist bromocriptine also depresses locomotor activity when first presented, but with repeated treatments results in an increase in locomotor activity (Hoffman and Wise 1992).

The inhibition of locomotor activity induced by quinpirole was expected and may be related to the stimulation of $\mathrm{D}_{2}$-type autoreceptors. Dopamine autoreceptors appear to be part of a negative feedback loop which, when stimulated, result in a decrease in the synthesis and release of dopamine as well as a decrease in the firing rate of dopamine cells (see Wolf and Roth 1987; Drukarch and Stoof 1990; Lynch 1991, for reviews). Dopamine autoreceptors are generally considered to be of the $\mathrm{D}_{2}$ type (but see Diana et al. 1991) and appear to be more sensitive to various dopamine agonists compared to postsynaptic $D_{2}$-type receptors (see Skirboll et al. 1979; Drukarch and Stoof 1990). Thus, although high doses of direct agonists such as apomorphine of ten increase locomotor activity, low doses typically result in an inhibition of activity due to selective autoreceptor stimulation (e.g., Mattingly et al. 1988). The initial inhibition of activity induced by quinpirole in the present study is consistent with this view. Moreover, the rapid tolerance that developed to the inhibitory effects of quinpirole also suggests autoreceptor involvement. That is, a number of electrophysiological studies have demonstrated that autoreceptors rapidly become subsensitive to dopamine agonists with repeated exposure (e.g., Rebec and Lee 1982). Hence, the progressive increase in activity observed in the present study with repeated quinpirole treatments may be related to the development of autoreceptor subsensitivity.

As discussed above, low doses of the mixed $D_{1} / D_{2}$ dopamine receptor agonist apomorphine usually produce hypoactivity and this decrease in activity has generally been attributed to selective $\mathrm{D}_{2}$ autoreceptor stimulation (e.g., Radhakishun and Van Ree 1987). The present results, however, indicate that stimulation of $\mathrm{D}_{1}$-type dopamine receptors with SKF 38393 can also produce locomotor hypoactivity. This finding suggests that the inhibitory effects of low doses of some dopamine agonists might be due to $D_{1}$ postsynaptic receptor stimulation rather than to simply $\mathrm{D}_{2}$ autoreceptor activation. Consistent with this view, other recent work suggests that the behavioral effects of low dose apomorphine treatments cannot be explained exclusively by selective autoreceptor activation (see Stahle and Ungerstedt 1989,
1990; Lynch 1991). Alternatively, it is possible that SKF 38393 reduced activity in the present study because the doses used stimulated both postsynaptic $D_{1}$ receptors and $\mathrm{D}_{2}$ autoreceptors. If this were the case, however, the SKF 38393-induced inhibition of activity should have progressively diminished over days in a manner similar to quinpirole. As noted previously, the SKF 38393-induced decrease in locomotor activity did not significantly change with repeated treatments. Likewise, SKF 38393induced grooming behavior in rats does not significantly increase with daily treatments (White et al. 1990; Niesewander et al. 1991). Thus, the possibility exists that the hypoactivity observed after mixed agonist treatments is mediated in part by $D_{1}$ receptors (cf, Vezina et al. 1991).

Although SKF 38393 treatments decreased locomotor activity across the 10 pretreatment days, SKF 38393-pretreated rats displayed significantly greater levels of activity in response to an apomorphine-challenge injection than rats pretreated with only vehicle. This finding is consistent with our previous work in which rats were treated daily with the mixed dopamine agonist apomorphine along with the $\mathrm{D}_{2}$ receptor antagonist sulpiride (Mattingly et al. 1991). Although this combination of drugs resulted in an acute decrease in locomotor activity across days, rats treated in this manner displayed a sensitized locomotor response to a subsequent challenge injection of apomorphine. Together these results suggest that repeated stimulation of the dopamine $\mathrm{D}_{1}$-type receptor alone is sufficient to induce the development of behavioral sensitization to the mixed dopamine agonist apomorphine. Based upon both behavioral and electrophysiological data, other researchers have also concluded that repeated dopamine $D_{1}$ receptor stimulation may be the crucial factor neccessary for the induction of agonist-induced behavioral sensitization (e.g., Braun and Chase 1988; Criswell et al. 1989; Henry et al. 1989; Stewart and Vezina 1989; Vezina and Stewart 1989; White et al. 1990; Henry and White 1991). It should be noted, however, that SKF 38393 is not a full but rather a partial $\mathrm{D}_{1}$ dopamine receptor agonist. Consequently, it might be argued that the increase in sensitivity to apomorphine observed in the present study following repeated SKF 38393 treatments could be due to an upregulation of $\mathrm{D}_{1}$ dopamine receptors. There are at least two arguments against this alternative interpretation. First, although an increase in dopamine $D_{1}$ receptors in the substantia nigra has been reported following chronic methamphetamine treatments (Ujike et al. 1991), chronic administration of SKF 38393 alone does not alter either the number or affinity of $D_{1}$ receptors (Rowlett, Mattingly, and Bardo, submitted for publication; Neisewander et al. 1991). Second, if the increase in sensitivity to apomorphine was due to the partial agonist effects of SKF 38393, then repeated SCH 23390 treatments should produce a similar increase in sensitivity to apomorphine. Repeated treatment with the dopamine $D_{1}$ receptor antagonist SCH 23390, however, does not result in an increased activity response to a subsequent challenge injection of apomorphine (see expt 3; Mattingly et al. 1991).

As discussed previously, we have found that the de- 
velopment of behavioral sensitization to the mixed $D_{1} /$ $\mathrm{D}_{2}$ dopamine agonist apomorphine could be completely blocked by the concurrent administration of the dopamine $\mathrm{D}_{1}$ receptor antagonist SCH 23390 (Mattingly et al. 1991). This finding suggests that repeated stimulation of the $\mathrm{D}_{2}$ receptor alone is not sufficient to induce behavioral sensitization. In the present study, however, rats previously given daily quinpirole $(3.0 \mathrm{mg} / \mathrm{kg})$ treatments displayed a greater activity response to apomorphine than rats pretreated with only vehicle. Consistent with this result, it has recently been reported that rats are also more sensitive to the locomotor-activating effects of cocaine after subchronic quinpirole pretreatments (Horger and Schenk 1991). These results, of course, clearly suggest the involvement of $\mathrm{D}_{2}$ receptors in the development of behavioral sensitization. One possible explanation of these findings is that repeated quinpirole treatments induce autoreceptor subsensitivity. Thus, when subsequently challenged with a mixed dopamine agonist such as apomorphine or cocaine, there is a greater net increase in postsynaptic dopamine receptor stimulation, which in turn, leads to greater locomotor activity. Interestingly, autoreceptor tolerance or subsensitivity was one of the earliest explanations for the development of behavioral sensitization (Muller and Seeman 1979; Robinson and Becker 1986), and a number of behavioral, electrophysiological, and neurochemical effects of repeated agonist treatments are consistent with this view (Rebec and Lee 1982; Henry and White 1991; Rowlett et al. 1991). But while an autoreceptor subsensitivity argument appears plausible, this explanation cannot account for the fact that the $0.3 \mathrm{mg} / \mathrm{kg}$ dose of quinpirole used in the present study did not increase subsequent sensitivity to apomorphine. Like the $3.0 \mathrm{mg} / \mathrm{kg}$ dose, this low dose of quinpirole resulted in a significant inhibition in activity that diminished across the 10 pretreatment days (see Fig. 3 ). This finding suggests that the $0.3 \mathrm{mg} / \mathrm{kg}$ dose of quinpirole also induced autoreceptor subsensitivity. Yet, this dose of quinpirole did not increase subsequent sensitivity to apomorphine. Thus, although autoreceptor subsensitivity may be a contributing factor to the development of sensitization, this latter finding suggests that some minimal level of postsynaptic $D_{2}$ receptor stimulation is also necessary to produce this effect. Consistent with this view, other evidence suggests that autoreceptor tolerance cannot account exclusively for the development of behavioral sensitization to mixed dopamine agonists (see Robinson and Becker 1986; Mattingly et al. 1991; Rowlett et al. 1991). Dopamine $\mathrm{D}_{2}$ antagonists, for example, do not block the development of sensitization to either apomorphine or amphetamine (Stewart and Vezina 1989; Vezina and Stewart 1989; Mattingly et al. 1991).

Interestingly, in experiment 3 , the effect of repeated $\mathrm{D}_{2}$ receptor stimulation with quinpirole on subsequent sensitivity to apomorphine was completely blocked by the $D_{1}$ receptor antagonist, $\mathrm{SCH} 23390$. This finding is consistent with previous work indicating that the development of behavioral sensitization to mixed $D_{1} / D_{2}$ dopamine agonists, such as apomorphine and amphetamine, may also be prevented by the blockade of $D_{1}$ dopamine receptors (Stewart and Vezina 1989; Vezina and Stewart 1989; Mattingly et al. 1991). Taken together, these results suggest that repeated dopamine $D_{2}$ receptor stimulation is neither necessary nor sufficient for the induction of behavioral sensitization. However, in the presence of $D_{1}$ receptor "tone", as in experiment 2, repeated $\mathrm{D}_{2}$ stimulation may contribute to the magnitude of the sensitization effect. Whereas, in the absence of $D_{1}$ "tone", repeated $\mathrm{D}_{2}$ receptor stimulation will not produce behavioral sensitization (expt 3; Stewart and Vezina 1989; Mattingly et al. 1991). These results are consistent with the idea of an "enabling" function for dopamine $D_{1}$-type receptors (see Clark and White 1987, for review).

Although the above interpretation accounts for the present results as well as our previous findings using selective antagonists with repeated apomorphine treatments (Mattingly et al. 1991), at least one alternative explanation should be noted. It could be argued, for example, that the ability of SCH 23390 to block the effects of repeated quinpirole or apomorphine treatments on subsequent sensitivity to apomorphine is due to a general depression of locomotor activity rather than to a specific blockade of dopamine $D_{1}$ receptors (cf Hirabayasi et al. 1991). Although this explanation cannot be exclusively ruled out on the basis of the present results, there are several arguments against this view. First, many treatments which significantly reduce locomotor activity do not block the development of behavioral sensitization. For example, the dopamine $\mathrm{D}_{2}$ antagonist sulpiride depresses activity and blocks the acute locomotor activating effects of apomorphine, but does not prevent the development of behavioral sensitization to apomorphine (Mattingly et al. 1991). Likewise, low doses of apomorphine inhibit locomotor activity but still result in the development of behavioral sensitization (Mattingly et al. 1988). Further, rats repeatedly treated with apomorphine in their home cage without any opportunity to explore the test environment display sensitization when subsequently challenged with apomorphine in the testing environment (Mattingly and Gotsick 1990). Also it may be noted that SKF 38393 treatments decreased activity in a dose-dependent manner in experiment 1 , but resulted in a greater activity response to a subsequent challenge dose of apomorphine. Finally, we have recently found that the same dose of SCH 23390 used in the present study does not block the development of behavioral sensitization to cocaine (Mattingly et al. 1992). Thus, 'treatments that depress locomotor activity in the test chambers do not always prevent the development of behavioral sensitization.

In conclusion, the present results indicate that repeated stimulation of either the $D_{1}$-type or $D_{2}$-type dopamine receptor can lead to greater activity in response to the mixed dopamine agonist, apomorphine. These findings are consistent with the view that repeated $D_{1}$ receptor stimulation is both necessary and sufficient to induce behavioral sensitization to apomorphine. Along with previous findings, the present results suggest that while $\mathrm{D}_{2}$ receptor stimulation may not be necessary for the development of behavioral sensitization to apomorphine, it does contribute to the magnitude of the 
effect. These findings lend additional support to the view that multiple pre- and postsynaptic mechanisms may be involved in the development of behavioral sensitization to dopamine agonists (cf Henry and White 1991).

Acknowledgements. This research was supported in part by grants from the Kentucky EPSCoR Committee and Morehead State University. The authors are grateful to Michael Bardo and Karen Lim for their helpful comments on an earlier version of this manuscript, and to Shannon Fauver, Tamara Hart, and Carmen Perkins for their assistance in behavioral testing.

\section{References}

Braun AR, Chase TN (1988) Behavioral effects of chronic exposure to selective $D-1$ and $D-2$ dopamine receptor agonists. Eur J Pharmacol 147:441-451

Clark D, White FJ (1987) Review: $D_{1}$ dopamine receptor - the search for a function: a critical evaluation of the $D_{1} / D_{2}$ dopamine receptor classification and its functional implications. Synapse 1:347-388

Criswell H, Mueller RA, Breese GR (1989) Priming of $D_{1}$-dopamine responses: long lasting behavioral supersensitivity to a $\mathrm{D}_{1}$-dopamine agonist following repeated administration to 6-OHDA-lesioned rats. J Neurosci 9:125-133

Diana M, Young SJ, Groves PM (1991) Modulation of dopaminergic terminal excitability by $\mathrm{D}-1$ selective agents: further characterization. Neuroscience $42: 441-449$

Drukarch B, Stoof JC (1990) D-2 dopamine autoreceptor selective drugs: do they really exist? Life Sci $47: 361-376$

Hirabayasi M, Saito T, Tadokoro S (1991) Differential sensitization to ambulation-increasing effect of metamphetamine after repeated administration to mice in activity cages of different sizes. Jpn J Pharmacol 57:91-97

Henry DJ, White FJ (1991) Repeated cocaine administration causes persistent enhancement of $D_{1}$ dopamine receptor sensitivity within the rat nucleus accumbens. J Pharmacol Exp Ther 258:882-890

Henry DJ, Greene MA, White FJ (1989) Electrophysiological effects of cocaine in the mesoaccumbens dopamine system: repeated administration. J Pharmacol Exp Ther 251:833-839

Hoffman DC, Wise RA (1992) Locomotor-activating effects of the $D_{2}$ agonist bromocriptine show environment-specific sensitization following repeated injections. Psychopharmacology 107:277-284

Horger BA, Schenk S (1991) Sensitization to cocaine's reinforcing and motor activating effects: different response to quinpirole preexposure. Soc Neurosci Aḅstr 17:683

Kalivas PW, Weber B (1988) Amphetamine injection into the ventral mesencephalon sensitizes rats to peripheral amphetamine and cocaine. J Pharmacol Exp Ther 245: 1095-1101

Kuczenski R, Leith NJ (1981) Chronic amphetamine: is dopamine a link in or a mediator of the development of tolerance and reverse tolerance? Pharmacol Biochem Behav 15:405-413

Lynch M (1991) Dissociation of autoreceptor activation and behavioral consequences of low-dose apomorphine treatment. Prog Neuropsychopharmacol Biol Psychiatry 15:689-698

Mattingly BA, Gotsick JE (1989) Conditioning and experiential factors affecting the development of sensitization to apomorphine. Behav Neurosci $103: 131 \mathrm{i}-1317$

Mattingly BA, Rowlett JK (1989) Effects of repeated apomorphine and haloperidol treatments on subsequent sensitivity to apomorphine. Pharmacol Biochem Behav 34:345-347
Mattingly BA, Gotsick JE, Salamanca K (1988) Latent sensitization to apomorphine following repeated low doses. Behav Neurosci 102:553-558

Mattingly BA, Rowlett JK, Graff JT, Hatton BJ (1991) Effects of selective $D-1$ and $D-2$ dopamine antagonists on the development of behavioral sensitization to apomorphine. Psychopharmacology 105:501-507

Mattingly BA, Hart T, Lim K, Perkins C (1992) Role of dopamine receptor subtypes in the development of cocaine-induced behavioral sensitization. Soc Neurosci Abstr 18:901

Muller P, Seeman P (1979) Presynaptic subsensitivity as a possible basis for sensitivity by long-term dopamine mimetics. Eur J Pharmacol 55: 149-158

Niesewander JL, Lucki I, McGonigle P (1991) Behavioral and neurochemical effects of chronic administration of reserpine and SKF-39383 in rats. J Pharmacol Exp Ther 257:850-860

Peris J, Zahniser NR (1989). Persistent augmented dopamine release after acute cocaine requires dopamine receptor activation. Pharmacol Biochem Behav 32:71-76

Radhakishun FS, Van Ree JM (1987) The hypomotility elicited by small doses of apomiorphine seems exclusively mediated by dopaminergic systems in the nucleus accumbens. Eur J Pharmacol 136:41-47

Rebec GV, Lee EH (1982) Differential subsensitivity of dopaminergic and neostriatal neurons to apomorphine with long term treatment. Brain Res 250:188-192

Robinson TE, Becker JB (1986) Enduring changes in brain and behavior produced by chronic amphetamine administration: a review and evaluation of animal models of amphetamine psychosis. Brain Res Rev 11:157-198

Rowlett JK, Mattingly BA, Bardo MT (1991) Neurochemical and behavioral effects of acute and chronic treatment with apomorphine in rats. Neuropharmacology 30:191-197

Skirboll LR, Grace A.A, Bunney BS (1979) Dopamine auto-and postsynaptic receptors: electrophysiological evidence for differential sensitivity to dopamine agonists. Science 206:80-82

Stahle L, Ungerstedt U (1989) Yawning and suppression of exploration in amphetamine-treated rats: incompatibility with the autoreceptor hypothesis. Psychopharmacology 97:553-560

Stahle L, Ungerstedt U (1990) Yawning and suppression of exploration induced by dopamine agonists: no relation to extracellular striatal levels of dopamine. Pharmacol Biochem Behav 35:201-209

Stewart J, Vezina P (1989) Microinjections of Sch-23390 into the ventral tegmental area and substantia nigra pars reticulata attenuate the development of sensitization to the locomotor activating effects of systemic amphetamine. Brain Res 495:401-416

Ujike H, Akiyama K, Nishikawa H, Onoune T, Otsuki S (1991) Lasting increase in $\mathrm{D}_{1}$ dopamine receptors in the lateral part of the substantia nigra pars reticulata after subchronic methamphetamine administration. Brain Res 540:159-163

Vezina P, Stewart J (1989) The effect of dopamine receptor blockade on the development of sensitization to the locomotor activating effects of amphetamine and morphine. Brain Res 499: 108-120

Vezina P, Blanc G, Glowinski J, Tassin JP (1991) Opposed behavioral outputs of increased dopamine transmission in prefrontocortical and subcortical areas: a role for the cortical d-I dopamine receptor. Eur J Neurosci 3:1001-1007

White FJ, Hu XT, Brooderson RJ (1990) Repeated stimulation of dopamine $\mathrm{D}-1$ receptors enhances the effects of dopamine receptor agonists. Eur J Pharmacol 191:497-499

Wolf ME, Roth RH (1987) Dopamine autoreceptors. In: Creese I, Fraser CM (eds) Dopamine receptors. Liss,. New York, pp 45-96 